\title{
Efficient institution in the context of environmental policies
}

\author{
Mihaela-Cornelia DAN, Ph.D. \\ Bucharest University of Economic Studies, Bucharest, Romania \\ mihaela.dan@fabiz.ase.ro \\ Emanuel PENA \\ Bucharest University of Economic Studies, Bucharest, Romania \\ emi.pena@yahoo.com \\ Ana Maria BACSIS \\ Bucharest University of Economic Studies, Bucharest, Romania \\ tanaseana1991@gmail.com
}

\begin{abstract}
In the context of new environmental paradigms for the efficient customization of both traditional and renewable energy systems, the international regulations aim to be effective sources of alignment. The control practices in a big state-owned enterprise are the concepts implemented in this paper into a multicriteria decision-making model for understanding, observing and accommodate the personnel for reaching high service quality. The best practices for effective policy design are alternatives in an Analytic Network Processes model designed and estimated by the staff in the audit department of the Romanian Regulatory Authority for Energy (RRAE). This model integrates all the national and international regulations at which the Romanian Regulatory Authority for Energy adhered and it determines what is the practical measures need to be taken at the level of each and every employee, in terms of individual forms of evaluation, so that principles regarding the implementation of the energy efficient systems produce tangible effects. The conceptual instrument considered for the effective alignment is the internal marketing. Internal marketing as a method built the foundation of a multi-criteria decision-making model whose alternatives are employees" evaluations forms. The model designed and estimated by staff in the audit department of the Romanian Regulatory Authority for Energy is developed using the analytic network processes theory (ANP) and the SuperDecisions software.
\end{abstract}

Keywords: environmental policy instruments, new energy paradigms, internal marketing, Romanian Regulatory Authority for Energy (RRAE), COSO, Analytic Network Processes (ANP).

\section{Introduction}

In order to increase the performance of different energy paradigms in promoting pattern changes in environmental policy instruments, the institutional organizational process needs to be conceived as a durable process which implies important collective and individual efforts. The model developed in this paper integrates all the national and international regulations at which the Romanian Regulatory Authority for Energy (RRAE) adhered and it determines what are the practical measures to be taken at the level of each and every employee, in terms of individual forms of evaluation, so that all the principles regarding the implementation of the energy efficient systems produce tangible effects. The conceptual instrument considered for the effective alignment is the internal marketing. Internal marketing as a method built the foundation of a multi-criteria decisionmaking model whose alternatives are employees" evaluations forms. This model designed and estimated by the audit department staff of the RRAE is developed using the analytic network processes theory (ANP) and the SuperDecisions software.

For the research carried out on RAE in this paper, a semi-structured interview conducted through questionnaires has been used. The respondents were persons working in several 
departments (audit department director, human resources department director, general secretary of the organization, president of the organization, two internal auditors). The main subjects which were covered referred to the correlation between general objectives established by the organization and specific objectives established for employees, methods used to assess employees" performances, methods used to motivate their employees, communication channels between departments, organizations of trainings for employees. Several relevant questions were formulated in order to stress the problems referred to the internal marketing of the organization and the internal control performed. Some information acquired from responses provided through questionnaires will be presented in the analysis of the problem observed. Nonetheless, in the following part of this chapter we will present problems identified within organization. In order to come up with sensible and prioritised suggestions about the alternatives for the optimal monitoring of performances, following the discrepancies already noticed in between the general objectives and the specific objectives, we used also a supplement research instrument called Analytic Network Process (ANP).

\section{Literature review}

Internal marketing is a concept defined as promoting the products of an organization to its employees in order to deliver consistently superior quality services to customers. This implies that the organization sees and treats its employees as "internal customers" in order to develop, motivate and retain them for a customer-oriented behaviour (Benoy, 1996, p. 54). The main goal of this approach is the satisfaction of internal customers, which is crucial when establishing their commitment to the company and consequently, when satisfying its clients (Caruana and Calleya, 1998). Hence, as Berry and Parasuraman (1991) state, treating employees as customers is the management philosophy of internal marketing. Another model of internal marketing is completed by Gronroos (2007) who divides it into strategic and tactical levels. Within his definition, he includes at strategic level "the adoption of supportive management styles and personnel policies", "customer service training" and "planning procedures". At tactical level, he implies activities such as "ongoing internal training", "informal internal communications", "internal market research" and "internal market segmentation". (Sargeant and Asif, 1998, p.68). Within the public entities there is generally a normative culture, where the focus is on a correct tracking of procedures, which are more important than the result. Moreover, within this type of organizational culture, the professional, moral etc. standards are elevated and reflect the attitude that the public entity has towards change.

In the implementation of the institutional organizational process, a durable process which implies important collective and individual efforts, a logical and chronological crossing of the following steps is necessary: the analysis of the objectives of the public entity, the designation of necessary activities and the establishment of their content, the creation of compartments, organizational structure and evaluation of its functionality. For improving organizational performance and governance, the Committee of Sponsoring Organizations (COSO) synthesized guidance for the management on how to implement and evaluate the effective enterprise risk management. According to COSO prototype, there are three main objectives of the Internal Control System, the efficiency of activities, the precision of the financial reports and the law enforcement and applicable regulations. In Romania, this model was first adopted by the public entities in 2005 and a first review was undertaken in 2015. Specific national legislation pieces (OMFP no. 946/2005, OSGG no. 400/2015, and OSGG no. 200/2016) consecrated the Code for Managerial Internal Audit of Public Entities. This Code includes Standards of Managerial Internal Audit. These 
standards define a minimal set of management regulations that must be followed by all public entities. Their aim is to create a uniform and coherent managerial internal audit model able to enable comparisons between entities of the same kind or within the same entity, at different moments in time and to make possible the highlighting of its economic activity and evolution. These standards also constitute a reference system, suitable for evaluating the evolution of the managerial internal audit models and the areas and directions subjected to alterations.

PICBE | 533

\section{Methodology}

Regulatory Authority for Energy (RAE), is an independent administrative authority, a legal entity, under governmental control, funded integrally from own income, with independent decisional, organizational and functional roles. Its function is to elaborate, approve and monitor the application of the mandatory regulations at national level, necessary for the functioning of the sector and the market of electrical energy, thermal energy and natural gas. The actual form of organization and functioning has been established in 2012. Between 2009 and 2012, RAE was organized and functioned under direct coordination of the Deputy Prime Minister, being funded by the national budget. Before, its regulatory activity took place within three entities: with regard to the sector and market of electrical and thermic energy: Regulatory Authority for Energy (RAE) - 1998-2007, with regard to the sector and market of natural gas: Regulatory Authority for Natural Gas (RANG) - 2000-2007, in regard to the formulation of engineering efficiency policy: Romanian Authority for Energy Conservation (RAEC) - 2002-2009.

In 2007, a singular regulatory authority for energy and natural gas was conceived, as the Regulatory Authority for Energy, (RAE), which took the attributions, budget, financial sources, personnel, rights and obligations from the Regulatory Authority for National Gas, which disbanded (fusion through absorption of RANG by RAE). In 2009, RAE also attained the Romanian Authority for Energy Conservation from the Economic Minister (fusion through absorption of RAEC by RAE).

RAE is led by one president and two vice-presidents. The president is the representative of RAE as independent administrative authority and legal person. His activity consists on giving orders and making decisions. He establishes the responsibilities, attributions and competences of the vice-presidents of RAE and of the general secretary through internal decisions. The financing of current expenses and the capital of RAE in ensured integrally through own revenues. RAE's revenue comes from rates from licences, authorizations and attestations, annual contributions to economic regulatory operators for electrical and thermic energy and natural gas, but also from other funds offered by international entities. The annual budget and expenses are to be approved by the president of RAE.

The regulatory committee composed of seven members (RAE president, two vicepresidents and four other members) was funded to approve the regulations for electrical and thermic energy and natural gas. The members are named or revoked during the meetings of the Parliamentary Committees. The activity of the Regulatory Committee develops under its own organizational and functioning regulations, approved by the president of RAE.

The Regulatory Committee is assisted by an Advisory Board, composed of 13 members, named as decision of the Prime-Minister, and has the function to ensure the harmony between the interests of the economic operators from the energy sector and their consumers, to evaluate the impact of the regulations imposed by RAE and to propose solutions to problems. Its activity develops under its own organizational and functioning regulations, approved by the president of 
RAE. On its website, RAE publishes information of public interest and exercises its attributes with respect to transparent, objective, proportional, impartial and neutral principals in the relationship with economic operators. The main attributions are as follows: issues, modifies and withdraws permits and licences, issues technical and commercial regulations, ensures access to electrical energy and natural gas networks, issues and approves methodologies for approving prices and rates, ensures the monitoring of the functioning of energy markets, promotes the production of energy from renewable sources.

In order to fulfil its attributes and competences, RAE puts into practice the following general objectives: the promotion of a safe European internal market of electrical energy and natural gas, competitive and durable from an environmental perspective and opening for the benefit of all clients and providers of the European Union and also, ensuring adequate conditions for an efficient and safe functioning of the electrical energy and gas networks, as long term objectives (1.GO. Facilitating the presence of European Energy Market at a national level), the development of competitive and functional regional markets, within the European internal market of electrical energy (2. GO. Regional Integrated Energy Markets), the withdrawal of restrictions regarding border trade with electrical energy and natural gas energy, in order to satisfy demands and facilitate an easier access of the national market in the European internal market of electrical energy and natural gas (3. GO. Integration of Internal Market in the European Energy Market), the development of a national energetic system which is safe, reliable and efficient, costumer oriented, allowing the promotion of energetic efficiency and the integration of renewable sources of energy, and also of the production distributed in transport and distribution networks. (4. GO. A safe Energetic System). Other tasks are the reinforcement of access to the network for the new capacities of production, especially through the elimination of obstacles which prevent the access of new participants to the electrical energy and natural gas market or the use of renewable sources of energy (5. GO. Free entrance in the Energy Market), the ensuring of given stimulants to the operators of electrical network / systems of natural gas and to other beneficiaries of electrical networks / systems of natural gas, in order to grow the functioning efficiency of energy transport and distribution systems and for establishing a more rapid integration within the market (6. GO. Correct benefits for the Energy providers), the consumer protection by ensuring effective competitive market, supporting vulnerable clients, imposing quality standards of public services from electrical energy and natural gas sector, by facilitating clients the access to their level of consumption data in the exchange process of the electrical energy and natural gas provider, and also by informing correctly and competently the consumers (7. GO. Standards for public services in energy), the guarantee of economic operators from energy and natural gas sectors to respect their obligations regarding transparency. (8. GO. Transparency).

In 2020, the main objective of RAE is to continually improve the regulatory activity by benefiting to a maximal level of the available human resources, in order to develop a modern, unitary regulatory framework, easy to access by all participants in the market, from the small consumer to the big corporations in the electrical energy and natural gas sector.

Externally, RAE collaborates with the regulatory authorities of regional states, including through cooperative agreements, with the Cooperative Authority in the Energy Domain (CAED) and European Commission, in order to create harmony to the regulatory framework for the regional market development, the regulations regarding border exchanges of electrical energy and natural gas, the management and allocation of interconnection capacities, without facilitating the fulfilment of their attributions and competences. 
Internally, RAE collaborates with the Competition Council, with the National Authority for Consumer Protection, with Financial Supervisory Authority, with ministers and other specialised bodies of the interested central and local public administrations, with consumers associations of electrical energy and natural gas, with professional associations within electrical energy and natural gas sector, with patronal and syndic associations.

The Regulatory Authority for Energy has correspondents in all countries that are part of

PICBE | 535 European Union. They have different organizations' forms: commissions, authorities, institutes, agencies and offices. Regardless of their organization form, they are independent financial, administrative and decisional entities. These organizations have the same role within their countries as RAE has in Romania, such as: creating predictability on constantly changing markets, liberalization and deregulation of the markets, ensuring that the gas and electricity markets are transparent and competitive, defending the vital interests of consumers, controlling and monitoring the electricity and gas markets, defining and maintaining a reliable and transparent tariff system.

There are some countries in which their representatives have additional duties attached to their tasks. For example, Germany has in addition to guarantee the deregulation and liberalisation of the markets for post, telecommunication and rail transport. Also, Italy and Bulgaria regulate, control and monitor the water market and Sweden assures a safe and efficient access to district heating.

The efficient internal controls system COSO prototype includes five components, which are enumerated below. First is the control environment at organizational management: it sets the bases of the internal control systems by providing a general structure. Second, the risk assessment implies the identification, evaluation and responses of the management regarding the risk that could affect the established objectives. Third, the control activities with regard to the policies, procedures, controls, other practices, which has as to assurance that the objectives established by the management are attained and the risks are diminished. Forth, the information and communication through which supports all the components of COSO, the communication between employees regarding the controls and the hand in of information in an adequate format and utility time so that the members of an organization could fulfil their duties. The fifth one is the monitoring and implies the supervision of internal controls by the management, the supervision by other external members of the process (internal auditors, monitoring organizations, etc.) or the application of independent methodologies of the type procedures and standard questionnaires completed by the employees in the process. There are general objectives rending into specific objectives required to be SMART. Individual objectives measured by performance indicators should embed the whole COSO framework and organizational culture as meta-approach. Therefore, deriving recommendations for an optimal internal marketing approach should be done in accordance with the individual performance regarded in the context of all the meta-approach previously described in detail. This is the only way in which adjustments are put in accordance with the organizational culture and with the individual objectives. Recognizing the specific connections, interconnections among all these conceptual and practical requirements, the internal audit department has rendered the task to deliver recommendations in accordance with all the above-mentioned criteria. While it is hard to keep in mind all the aspects regarding the mission, vision, integration of the company among other similar companies, the formalisation of an ANP Model illustrating all the connections and their intensity weighting offer not only an integrative view, but also, the possibility to assess the importance of the alternative recommendations in an integrated view. Moreover, performing sensitivity analyses after estimating the model offers the possibility to deliver the best recommendation in accordance 
with the specific or individual objectives of particular interest. As it can be seen, there are a lot of things that should be reorganized for cultivating a better internal marketing and control approach within RAE. In general, enabling innovations in an entity requires a long process which is developed during a period of time, so that the employees get familiarized with the new working environment and the management changes and develops the initial scheme according to the results acquired up to that moment. The management realises that it has to implement those solutions that have the greatest impact over developing the organization's performances. Having in mind that they cannot be enforced all in the same time, prioritizing the problems which are to be solved would be an agreeable idea. The process of prioritization will be performed by using ANP.

For the purpose of this research the following activities were undertaken: research of general and specific legislation that defines and regulates the way RAE is organized and operates, observation and analysis of the activities carried out in several departments, several documents, procedures already enforced and results, access the RAE's organizational chart, Internal Regulation Policy, job descriptions, list of procedures, list of specific objectives for different departments, performance indicators established for executing the specific goals, procedure of yearly evaluation of employees professional performances, individual performance reviews, going through audit reports in order to understand the control environment and organizational culture, the issues identified by internal auditors and their recommendations for activity improvements.

For identifying certain problems, as an instrument, a questionnaire has been distributed to ten employees from different departments and positions. The 22 questions were formulated in a strategic way in order to obtain accurate and measurable responses about: the organization's mission, role, objectives and priorities, the way positions are filled, the way employees are trained and their work evaluated, the vertical and inter-department communication, the degree of employees' involvement in managerial activity / decision-making, service quality, behaviour, cooperation and salary payment, motivation, satisfaction and evaluation.

In order to collect relevant answers, the personnel involved in answering the questionnaire had five evaluation levels: $1=$ "Not at all", $2=$ "To a small extent", 3 = "Moderate", 4 = "To a great extent", $5=$ "To a very great extent". After summarizing the answers, analysing the documents and undertaking discussions with the department managers, several problems have been identified.

These solutions are to be prioritised taking into account certain universally available criteria and using ANP method in order to highlight / demonstrate IM's applicability at the level of this kind of organization.

ANP is a decision-making tool created by Thomas Saaty, which has as purpose to help users instituting a relative weight regarding the criteria that cannot be measured objectively (Saaty, 2008). There are four steps in the ANP. In the first step, the problem is expressed. In the second step, a hierarchy or a network is being created. The third step consists of constructing comparison matrices based on the elements of the network created in the previous step. One matrix compares the elements that are on the same level, and then elements from different hierarchical levels will be compared. In the fourth step, the results of the comparison made in the previous step will be used to arrange the elements in the levels below. This step is repeated until one will obtain the final weights for the alternatives.

For sure, determining the structure of a decision problem and implicit the particular form of the ANP model is a creative process yet subject to the consensual agreement of the experts involved. This process implicates categorizing factors that relate to that particular problem. If the 
model is structured in a form of a hierarchy, transferring influences top-down, the factors are categorized in four levels of hierarchy and in descending order are as following: goal, criteria, subcriteria and alternatives. In order to find elements for each level, the context of the problem must be well understood and possible solutions and participants that could help in solving the issue should be taken into consideration. The end result should be a hierarchy that has one level for each of the following: goal, attributes, issues, and stakeholders. The two main purposes of a hierarchy are to ensure the overall view of existing relationships between elements and to check if the elements present at the same level have similar magnitudes. If feedback connections are considered appropriate, a hierarchy can easily be transformed into a network through the removal of the goal cluster.

Elements are different, and they take a different cut of problems at different levels. Not necessarily will an element be a criterion for all the elements placed in lower levels. For instance, when one level deals with social problems, the very next level might evaluate political factors in respect to social factors. The way the hierarchy works is such that the elements with a more general character are placed in the superior levels of the hierarchy, while the more particular ones will be at the lower levels. Therefore, the comparison will be more meaningful.

One should know that the comparisons are based on a scale of numbers, where one has to decide how much he or she prefers the chosen answer in relation to the other element of comparison. The scale of numbers consists of numbers between 1 and 9 , where 1 means equally important and 9 means extremely important. In the scale of measurement there are three parts: the set of elements, numbers used, and the mapping of elements according to chosen numbers.

The feasible part of this method is that the chosen criteria can refer to unclear or intangible issues. In this criterion relative measurement is used, taken from the standard scales and the normalizing process. ANP is a useful tool as it allows comparison between the pairs of elements with an element from the hierarchy. The grading for the comparisons is based on one's standards or experiences.

\section{Results and discussions}

Following the theoretical descriptions in the chapters above about the categories and the subcategories with their correspondences, all the information was organized in clusters with nodes and connections in between nodes. These clusters with their node constituents are listed below.

The clusters that we can find attached to this model are:

1. Organizational Culture Survey;

2. COSO;

3. General Objectives;

4. Specific Objectives;

5. Smart;

6. Individual Objectives;

7. Performance Indicators;

8. Alternatives.

The nodes associated with every cluster represent characteristics of these clusters and it will be presented in the following lines.

The cluster 1. Organizational Culture Survey has the next three nodes:

1.1. Clear definition and dissemination of objectives and priorities;

1.2. Adequate understanding of the organization's missions; 
1.3. Adequate matches regarding hiring.

The cluster 2. COSO consists of:

2.1. Control Environment

2.2. Risk Assessment

2.3. Control Activities

2.4. Information \& Communication

2.5. Monitoring Activities

The cluster 3. General Objectives has eight nodes:

3.1. Facilitating the presence the presence of European Energy Market at a national level;

3.2. Integration of Internal Market into the Regional Market;

3.3. Integration of Internal Market in the European Energy Market;

3.4. A safe Energetic System;

3.5. Free entrance in the Energy Market;

3.6. Correct benefits for the Energy providers;

3.7. Standards for public services in Energy;

3.8. Transparency.

The cluster 4. Smart is composed of five nodes:

4.1. $\mathrm{S}$ - specific;

4.2. $\mathrm{M}$ - measurable;

4.3. A - attainable;

4.4. $\mathrm{R}$ - realizable;

4.5. $\mathrm{T}$ - timely.

This cluster is associated especially with general and specific objectives in order to obtain those alternative that have the greatest impact over organization. It is connected with general objectives and specific objectives because these objectives require to be SMART. Also, it is interconnected to alternatives cluster because the goal is to obtain prioritized solutions.

The cluster 5. Specific Objectives consists of:

a. Annually improving of added value,

b. Implementation of internal control instruments for annually improving

c. Assuring a good management of the annual terms.

It is derived from the general objectives cluster and has as derivative individual objectives cluster because these aims are established in accordance to specific goals. Specific objectives are required to be SMART and, consequently, is interconnected to SMART cluster.

The cluster 6. Individual Objectives cluster consists of:

6.1. Improving quality of the job description files;

6.2. Improving the process of annual evaluation of performances in a specific time;

6.3. Completing of inheritance declarations in accordance with the deadline.

This cluster is derived from the specific objectives cluster and has a derivative cluster namely performance indicators. Likewise, it is interconnected with alternatives cluster in order to obtain realistic solution that will be implemented within RAE.

The cluster 7. Performance Indicators comprises three nodes:

7.1. The progress of the work required;

7.2. The number of registered inadequacies;

7.3. Respecting project deadlines. 
It is interconnected only with alternatives cluster because it is the most specific tool that can be attributed to an employee in order to be monitored.

The cluster 8. Alternatives consists of six recommendations which represent the nodes from the cluster:

8.1. A strategy for 3-5 years;

8.2. Reassessment of the general objectives;

PICBE | 539

8.3. Reassessment of the specific objectives;

8.4. Integrating performance indicators;

8.5. Establishing performance indicators for individual objectives;

8.6. The optimal fit of the individual objectives to every employee.

Nodes in this cluster are connected in a complex way with another nodes in different clusters. For instance, the first node has a direct relationship with nodes in three different clusters namely: general objectives, specific objectives and organizational culture survey. Alternatively, the second node is interconnected only with general objectives cluster because it refers only to the reassessment of them. The reassessment of specific objectives node is connected with the specific objectives cluster.

The Super Decisions software was used for obtaining a prioritization of the recommendations designed to help RAE to solve their problems identified in this case study.

Following the traditional procedure of estimating a model in the consensus mode, all the members of the Audit Department were gathered together in five consecutive one hour and a half meetings. In the first meeting, it was presented the skeleton of the model, opinions about its completion were gathered and assembled and all the suggested connections in between nodes and clusters were established in full consensus. In the next three meetings there were evaluated all the pairwise comparisons. Each time, when inconsistency index associated with a decision matrix was above the recommended level of 0.1 , the inconsistency report was generated and experts were asked to revise their estimations and deliver a commonly agreed new pairwise comparison. This procedure was repeated with the whole group together until the inconsistency index fall under the threshold of 0.1. At the end of the fourth meeting, the synthesized results were generated and presented to the group. In the fifth meeting there was explained the procedure of the sensitivity analysis and several options were chosen for numerical illustration. The ANP model is shown in Figure 1 below.

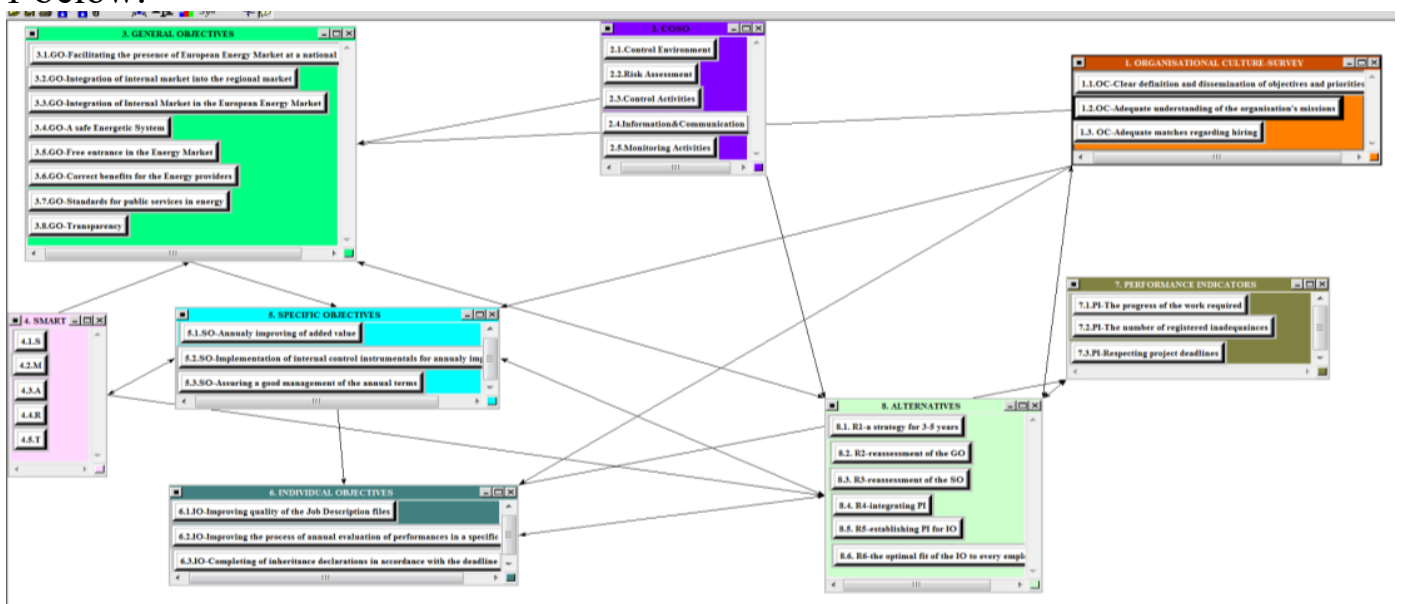

Figure 1: The ANP Model 
The synthesized results refer to the comparative weights of importance for the alternatives. The alternatives are the suggested improvements and the suggested improvements are decided in accordance with all firm's general and subjective objectives. It is therefore a big step to an integrative way of suggesting improvements, in accordance with all the macro and micro policies at the firm's level.

The specific numbers, as derived from the synthesized model are shown in Figure 2.

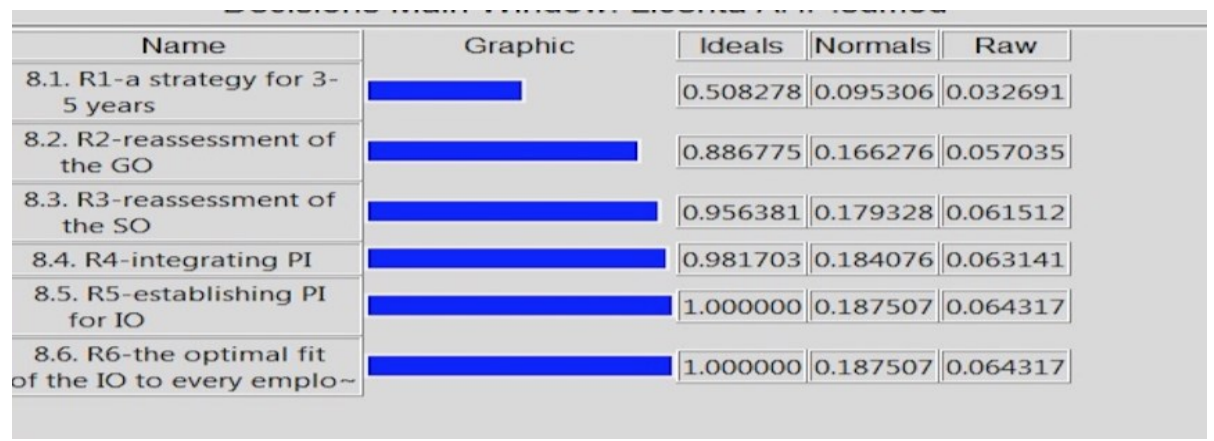

Figure 2: The synthesized ANP Model

The R5 - establishing performance indicators for individual objectives and 8.6 - the optimal fit of the individual objectives to every employee have the biggest weight because they are not implemented yet, and represent an immediate measure that the management has to take in order to solve the issues encountered by RAE. These are the most important because the individual objectives do not derive from specific objectives and the first are not accompanied by performance indicators able to measure the extent to which the objectives are fulfilled. These performance indicators are not defined in The Professional Performances Evaluation Review. In RAE, there is not yet a system for reporting the specific indicators fulfilment. This system should have a monitoring function and be able to inform the middle and upper management about any possible deviation from objective fulfilment, activity risks and mitigate the effects of unforeseen events. The last two recommendations have the same value because it was considered that individual objectives cannot be measured without performance indicators and they have scored with same values because their importance is of an equal extent.

The R4 - integrating performance indicators alternative which refer to integrate performance indicators has a value of 0.184076 , which represents an appropriate value towards the last two alternatives which have 0.187507 . This happens because this alternative reinforces the previously two measures.

The R3 - reassessment of the specific objectives alternative, reassessment of the specific objectives, has a value of 0.179328 . It represents the fourth value on the list of the comparative priorities because these objectives are already established by the management of the organization. They need only to be reassessed because they are not SMART.

The R1 - a strategy for 3-5 years alternative renders the smallest importance because of the time frame, not being the most urgent thing to do in the present. RAE has already a strategy implemented, but that one is not specific and measurable.

Sensitivity analysis with respect to the main categories - expressed as three nodes - in the ORGANIZATIONAL CULTURE SURVEY cluster is best expressed through the rate of change. 
The actual values of the alternatives representing the recommendations suggested in the meta-context of the ANP model correspond to a control parameter of 0.5. If the importance of the node 1.1.OC - Clear definition and dissemination of objectives and priorities would be increased by $50 \%$ that would correspond to a value of the control parameter of 0.75 . The comparative values under these two circumstances are shown in Figures 3 and 4.

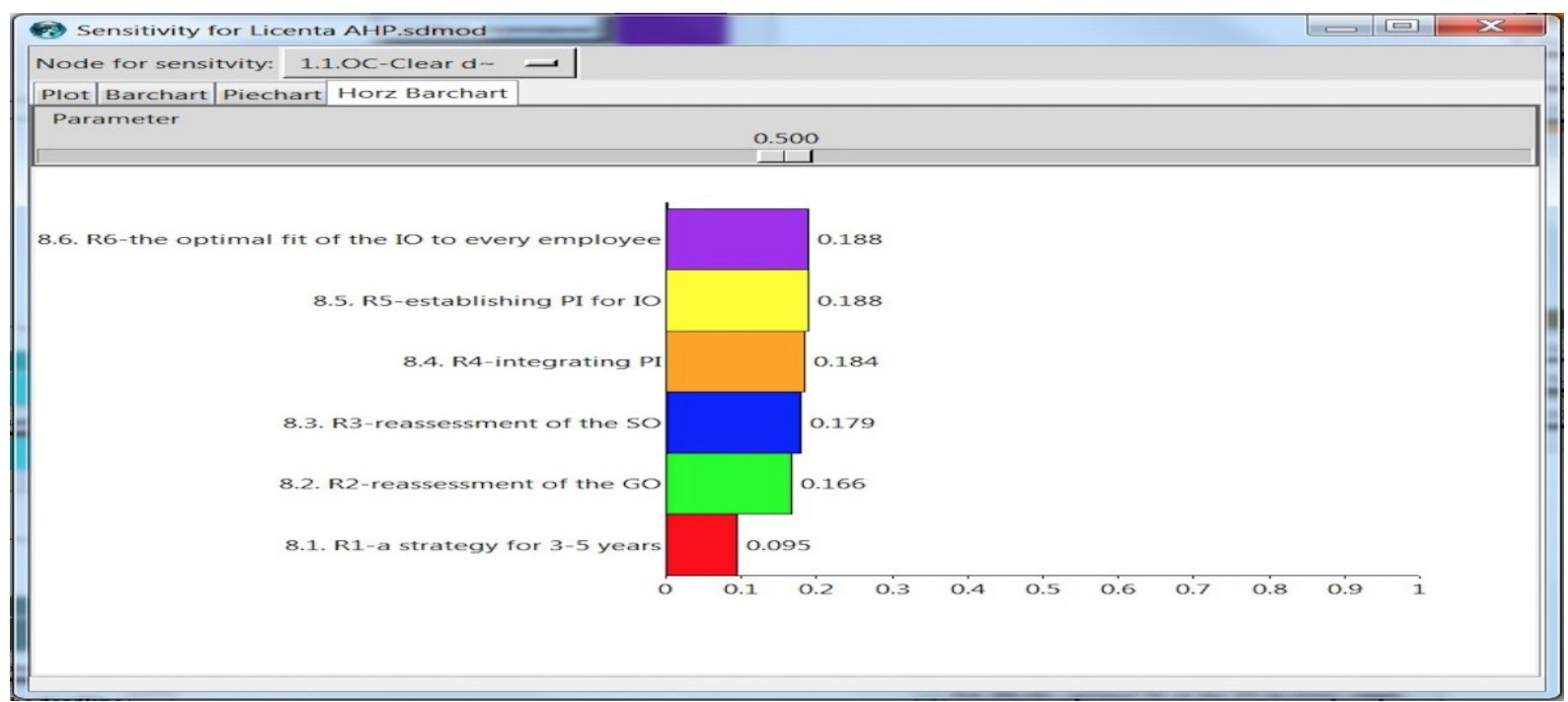

PICBE | 541

Figure 3: Parameter 0.5 with respect to 1.1

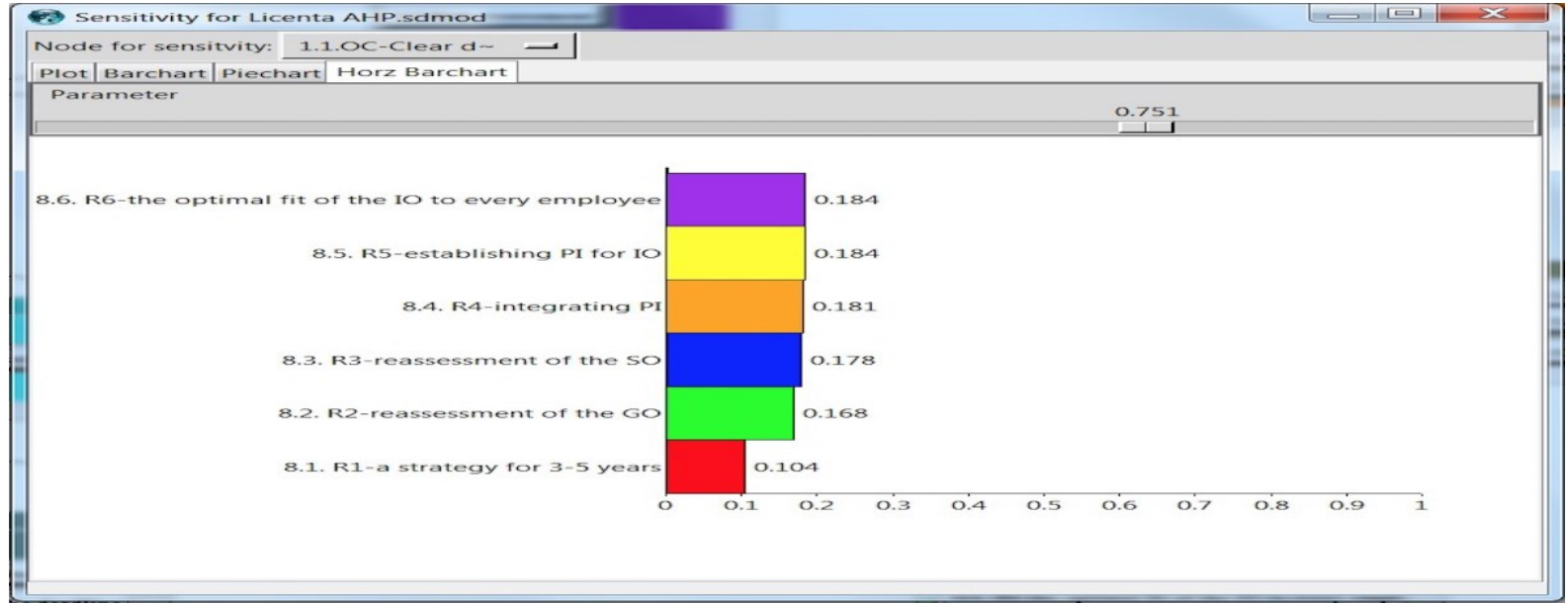

Figure 4: Parameter 0.75 with respect to 1.1

Results confirm that the clearer are the objectives set the most sensitive is the formulation of a strategy for the next 3-5 years. On the other hand, the R6 - the optimal fit of the individual objectives to every employee and the R5 - establishing performance indicators for individual objectives are less sensitive to the extra time spend for setting more clearer the future objectives.

The reassessment of the specific objectives seems to be the least sensitive with respect to the extra time for a better formulation of the 1.1 clear definition and dissemination of objectives and priorities. While these results confirm the common perceptions, the particular numerical values give also a much more close numerical sense about the scale of sensitivity. 
If the importance of the node 1.2.OC - adequate understanding of the organization's missions would be increased by $50 \%$ that would correspond to a value of the control parameter of 0.75. The comparative values under these two circumstances are shown in Figures 3 and 4,

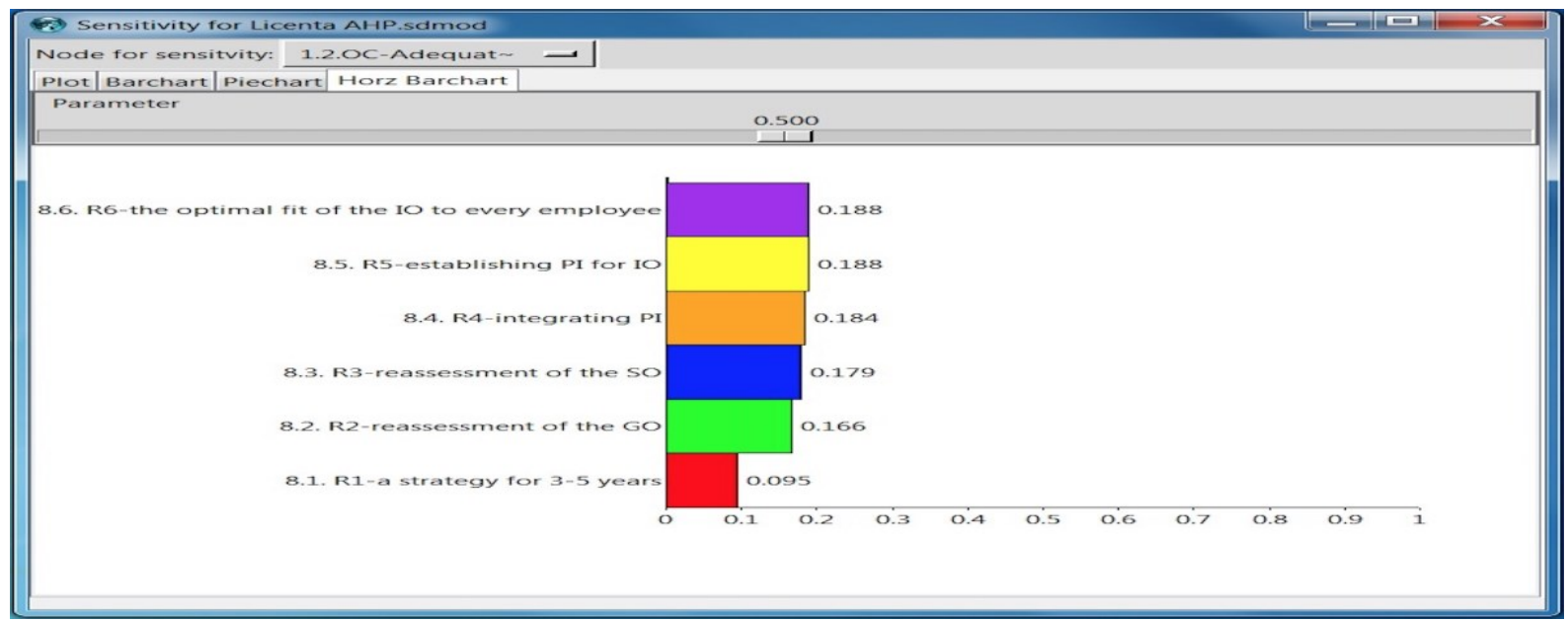

PICBE $\mid 542$

Figure 3 : Parameter 0.5 with respect to 1.2

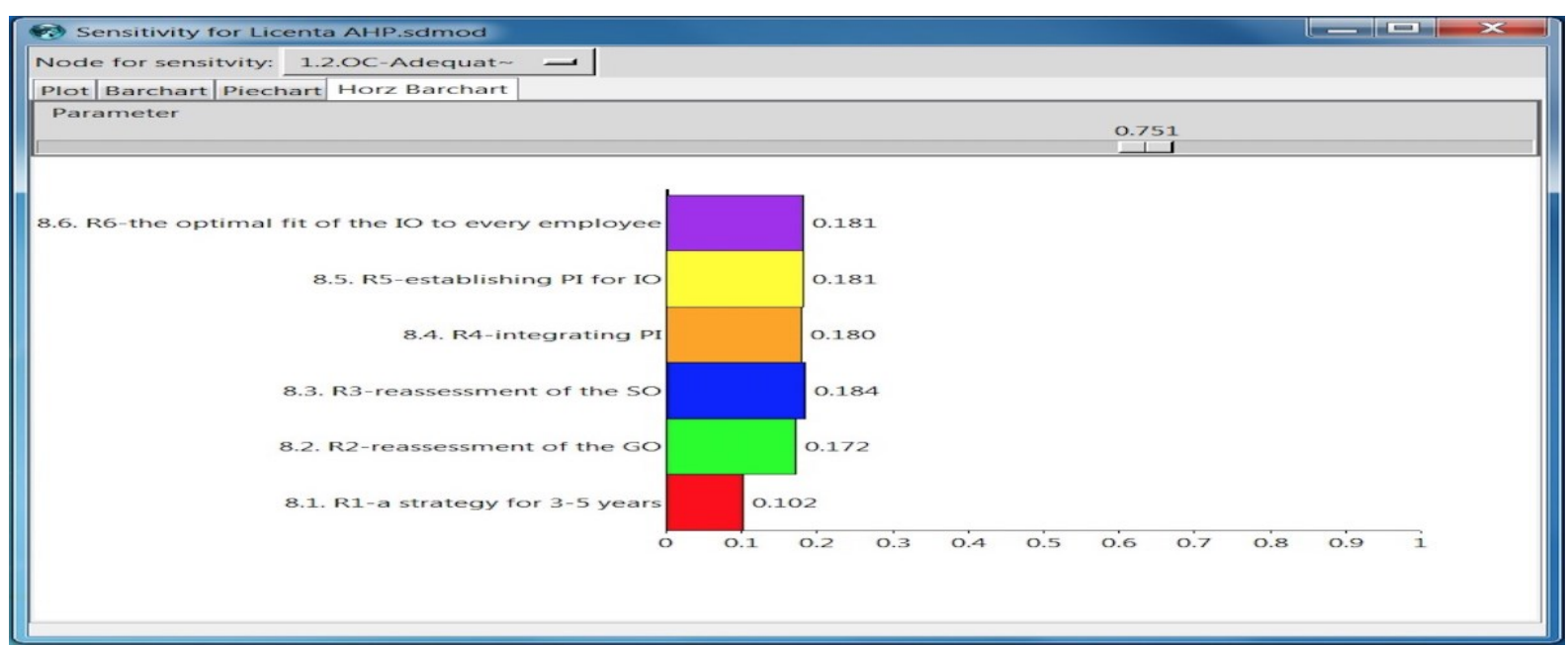

Figure 4: Parameter 0.75 with respect to 1.2

The changes in the weight of importance of the alternatives are shown in Table 1 and based on this are derived the correspondence rates of change: 
Table 1

\begin{tabular}{|l|l|l|l|l|}
\hline $\begin{array}{l}\text { 1.2.OC-Adequate } \\
\text { understanding of the } \\
\text { organization's missions }\end{array}$ & $\begin{array}{l}\text { Current value of } \\
\text { control parameter } \\
0.5\end{array}$ & $\begin{array}{l}50 \% \text { increase in } \\
\text { the importance of } \\
\text { the criterion 1.1 } \\
\text { corresponding to } \\
\text { the control } \\
\text { parameter } 0.75\end{array}$ & Rate of change \\
\hline $\begin{array}{l}\text { R6-the optimal fit of } \\
\text { the IO to every } \\
\text { employee }\end{array}$ & 0.188 & 0.181 & $(0.181-0.188) / 0.188$ & -0.037 \\
\hline $\begin{array}{l}\text { R5 - establishing PI for } \\
\text { IO }\end{array}$ & 0.188 & 0.181 & & \\
\hline R4 - integrating PI & 0.184 & 0.180 & $(0.181-0.188) / 0.188$ & -0.037 \\
\hline $\begin{array}{l}\text { R3 - reassessment of } \\
\text { the SO }\end{array}$ & 0.179 & 0.184 & $(0.180-0.184) / 0.184$ & -0.021 \\
\hline $\begin{array}{l}\text { R2 - reassessment of } \\
\text { the GO }\end{array}$ & 0.166 & 0.172 & $(0.184-0.179) / 0.179$ & 0.027 \\
\hline $\begin{array}{l}\text { R1 - a strategy for 3-5 } \\
\text { years }\end{array}$ & 0.095 & & & 0.036 \\
\hline
\end{tabular}

PICBE | 543

Source: Authors' own research

Results confirm that the clearer are the objectives set the most sensitive is the formulation of a strategy for the next 3-5 years. On the other hand, the R6 - the optimal fit of the individual objectives to every employee and the R5 - establishing performance indicators for individual objectives are less sensitive to the extra time spend for setting more clearer the future objectives.

The reassessment of the specific objectives seems to be the least sensitive with respect to the extra time for a better formulation of the 1.1 clear definition and dissemination of objectives and priorities. While these results confirm the common perceptions, the particular numerical values give also a much more close numerical sense about the scale of sensitivity.

If the importance of the node 1.2.OC - adequate understanding of the organization's missions would be increased by $50 \%$ that would correspond to a value of the control parameter of 0.75. The comparative values under these two circumstances are shown in Figures 3 and 4. 


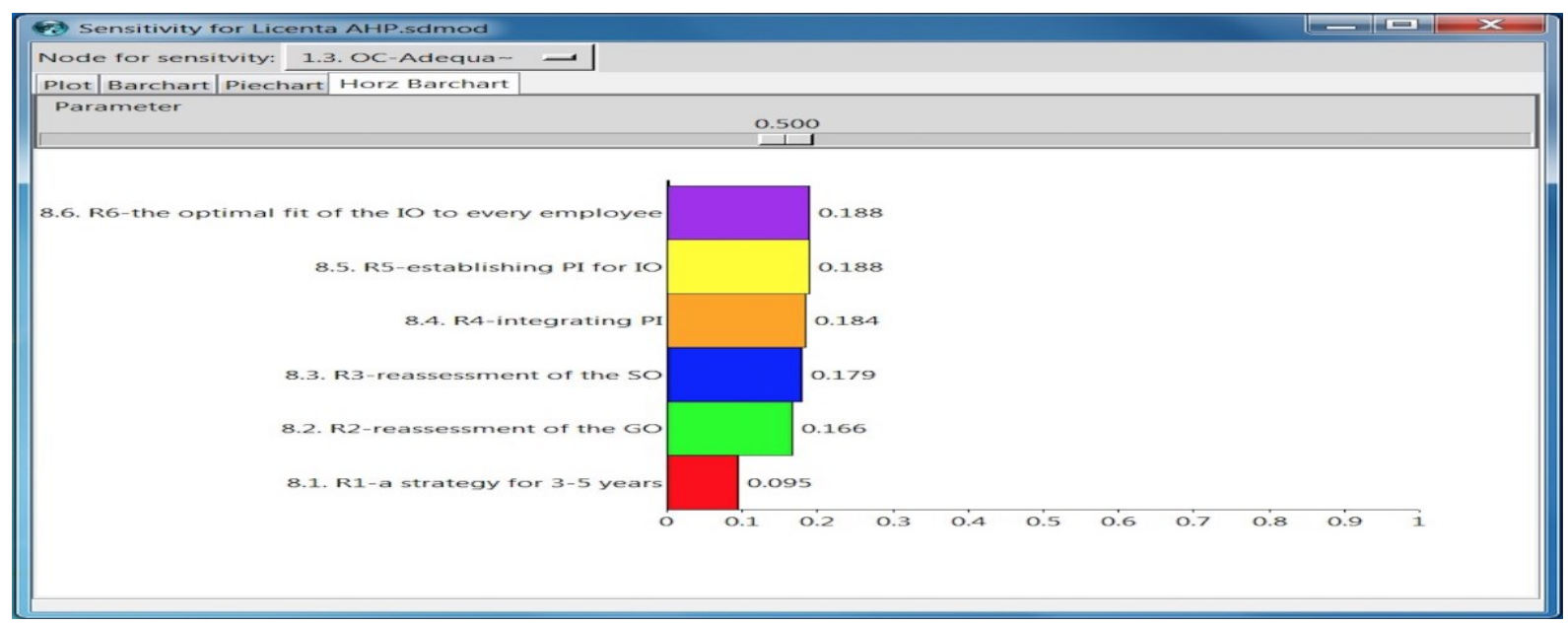

PICBE | 544

Figure3: Parameter 0.5 with respect to 1.3

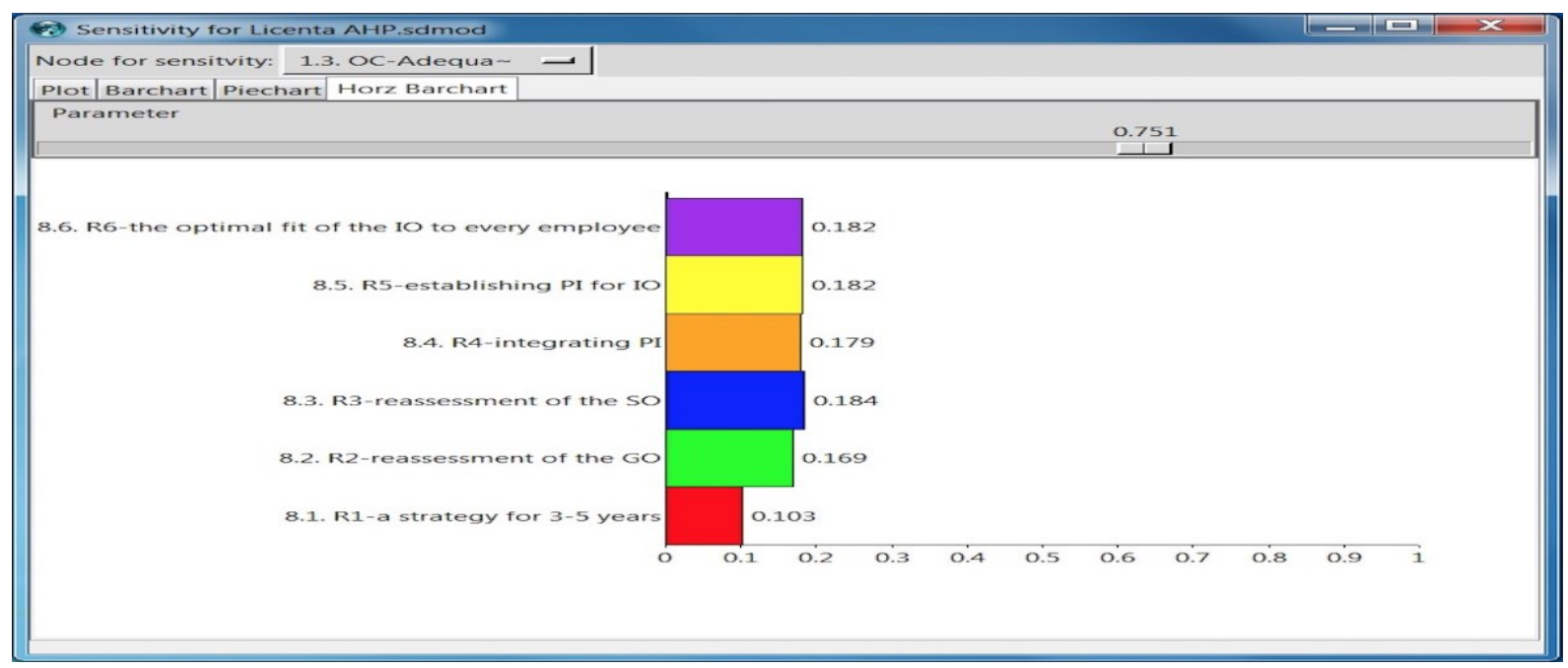

Figure 4: Parameter 0.75 with respect to 1.3

The changes in the weight of importance of the alternatives are shown in the table 3 and based on this are derived the correspondence rates of change:

Table 1

\begin{tabular}{|l|l|l|l|l|}
\hline $\begin{array}{l}\text { 1.3.OC-Adequate } \\
\text { matches regarding } \\
\text { hiring }\end{array}$ & $\begin{array}{l}\text { Current value of } \\
\text { control parameter } \\
0.5\end{array}$ & $\begin{array}{l}50 \% \text { increase in } \\
\text { the importance of } \\
\text { the criterion 1.1 } \\
\text { corresponding to } \\
\text { the control } \\
\text { parameter } 0.75\end{array}$ & Rate of change & \\
\hline $\begin{array}{l}\text { R6-the optimal fit of } \\
\text { the IO to every } \\
\text { employee }\end{array}$ & 0.188 & 0.182 & $(0.182-0.188) / 0.188$ & -0.031 \\
\hline $\begin{array}{l}\text { R5-establishing PI for } \\
\text { IO }\end{array}$ & 0.188 & 0.182 & $(0.182-0.188) / 0.188$ & -0.031 \\
\hline
\end{tabular}

DOI: 10.2478/picbe-2020-0050, pp. 531-547, ISSN 2558-9652| Proceedings of the $14^{\text {th }}$ International Conference on Business Excellence 2020 


\begin{tabular}{|l|l|l|l|l|}
\hline R4-integrating PI & 0.184 & 0.179 & $(0.179-0.184) / 0.184$ & -0.027 \\
\hline $\begin{array}{l}\text { R3-reassessment of } \\
\text { the SO }\end{array}$ & 0.179 & 0.184 & $(0.184-0.179) / 0.179$ & 0.027 \\
\hline $\begin{array}{l}\text { R2-reassessment of } \\
\text { the GO }\end{array}$ & 0.166 & 0.169 & $(0.169-0.166) / 0.166$ & 0.018 \\
\hline $\begin{array}{l}\text { R1-a strategy for 3-5 } \\
\text { years }\end{array}$ & 0.095 & 0.103 & $(0.103-0.095) / 0.095$ & 0.084 \\
\hline
\end{tabular}

PICBE $\mid 545$

Results confirm that the clearer are set the objectives the most sensitive is the formulation of a strategy for the next 3-5 years. On the other hand, the R6 - the optimal fit of the individual objectives to every employee and the R5 - establishing performance indicators for individual objectives are less sensitive to the extra time spend for setting more clear the future objectives.

The R2 - reassessment of general objectives seems to be the least sensitive with respect to the extra time for a better formulation of the 1.2 adequate understanding of the organization. While these results confirm the common perceptions, the particular numerical values give also a much more close numerical sense about the scale of sensitivity.

\section{Conclusion}

The study carried out throughout this paper was set out to explore the concepts of internal marketing and control systems within an organization, ideas framed around a case study performed at RAE. After an in-depth research on the existing models at other firms and also at RAE, several recommendations on ways of improvement have been established, such as the following: improvement of the evaluation of individual's professional performance process by setting individual objectives, establishing the performance level for each employee according to the performance indicators and identifying the needs of professional training, providing an example of the departments' specific and individual objectives by executing the SMART requirements, setting out measurable individual performance indicators for employees in order to assess employees' professional performances on their own established objectives, designing a report system, Balance scorecard, for introducing general specific and individual objectives, in order to identify, examine and organize the activities of the personnel, designing a strategy for 3-5 years. The most important element of the internal control system implementation is the implementation of the COSO Model, with its five key elements: control environment, performance and risk management, control activities, information, communication and monitoring activities.

The disadvantages of the Standard Objectives implementation identified during the research are the following: specific targets and common functions are not identified and clearly stated, departments' specific objectives do not respect under any circumstances the SMART requirements and performance indicators are not defined, individual objectives measured by indicators have not been identified.

Recommendations may be implemented depending on the financial and human resources availability and competences. Furthermore, top and line managers of RAE must be trained accordingly in order to provide high quality service and build strong relationships with the customers. 


\section{References}

A Berry, L. (1981), The employee as customer, Journal of Retail Banking, Vol. 3, Issue 1, pp. 825

Berry, L.L. and Parasuraman, A. (1991), Marketing Services: Competing Through Quality, The Free Press, Oxford

Caruana, A., \& Calleya, P. (1998), The effect of internal marketing on organizational commitment among retail bank managers, The International Journal of bank Marketing, Volume 16, Issue 3, pp. 108-116

Collins, B. and Payne, A. (1991), Internal marketing: a new perspective for HRM, European Management Journal, Vol. 9, Issue 3, pp. 261-270

Danik, L., and Kowalik, I. (2013), The studies on born global companies - a review of research methods, Journal of Economics \& Management, Vol. 13, Issue 1, pp. 10-26

Drummond, H. (2000), Introduction to Organizational Behaviour, Oxford University Press

Foreman, S.K. and Money, A.H. (1995), Internal marketing: concepts, measurement and application, Journal of Marketing Management, Vol. 11, Issue 8, pp. 755-768

Frost, F.A. and Kumar, M. (2000), INTSERVQUAL - an internal adaptation of the GAP model in a large service organization, Journal of Services Marketing, Vol. 14, Issue 5, pp. 358-377

Gilmore, A. and Carson, D. (1995), Managing and marketing to internal customers, in Glynn, W.J. and Barnes, J.G. (Eds), Understanding Service Management, John Wiley, Chichester, pp. 295-321

Gorchels, L.M. (1995), Trends in marketing services, Library Trends, Vol. 43 No. 3, pp. 494-509

Greene, W., Walls, G. and Schrest, L. (1994), Internal marketing: the key to external marketing success, Journal of Services Marketing, Vol. 8, Issue 4, pp. 5-13

Gronroos, C. (2000), Service Management and Marketing: A Customer Relationship Management Approach, 2nd edition, John Wiley, Chichester

Gronroos, C. (2007), Service management and marketing: customer manager in service competition, 3rd edition, John Wiley, Chichester

Helman, D., and Payne, A. (1992), Internal marketing: Myth versus Reality, Cranfield School of Management

Hicks, H. G. and Gullett, C. R. (1976), The Management of Organizations, 3rd edition, McGrawHill

Joseph, Benoy, W. (1996), Internal Marketing Builds Service Quality, Journal of Health Care Marketing, Vol. 16, Issue 1, pp. 54-59

Kotler, P. (2001), A Framework for Marketing Management, Prentice-Hall, Upper Saddle River, NJ

Laurie J. Mullins (2010), Management \& Organizational Behaviour - 9th edition, Financial Times Prentice Hall

Lawler, E. E. (1976), Control Systems in Organization, in Dunette, M. D. (ed.) Handbook of Industrial and Organizational Psychology, Rand McNally

Lewis, B. and Entwistle, T. (1990), Managing the service encounter: a focus on the employee, International Journal of Service Industry Management, Vol. 1, Issue 3, pp. 41-52

Mei-Hwa Lin, Hiu Lam Choy, William W. Cooper, Hsihuia Chang (2008), The Sarbanes-Oxley act and the production efficiency of public accounting firms in supplying accounting auditing and consulting services: an application of data envelopment analysis, International Journal of Services Sciences, Vol. 1, No. 1, pp. 3-20 
Parasuraman, A., Zeithaml, V. A., Berry, L. L., (1990), Delivering quality service: balancing customer perceptions and expectations, The Free Press, New York

Rafiq, M. and Ahmed, P.K. (2000), Advances in the internal marketing concept: definition, synthesis and extension, The Journal of Services Marketing, Vol. 14, Issue 6, pp. 449-462

Rafiq, M. and Ahmed, P.K. (2000), The scope of internal marketing: defining the boundary between marketing and human resource management, Journal of Marketing Management, Vol. 9, Issue 3, pp. 219-232

Robert K. Yin (2009), Case Study research - Design and Methods, 4th edition, SAGE Publication, Los Angeles.

Saaty, T. (2008), Decision making with the analytic hierarchy process, International Journal of Services Sciences, Vol.1 No.1, pp. 83-98

Sargeant, A., \& Asif, S. (1998), The strategic application of internal marketing: an investigation of UK banking, International Journal of Bank Marketing, Vol. 16, Issue 2, pp. 66-79

Tulgan, B. "Winning the Talent Wars" (2001), in Crainer, S. and Dearlove, D. (eds), Financial Times Handbook of Management, 2nd edition, Financial Times Prentice Hall, p. 351.

Wilson, F. (2004), Organizational Behaviour and Work: A Critical Introduction, 2nd edition, Oxford University Press

Zeithaml, V. A. and Bitner, M. J. (1996), Services Marketing, McGraw-Hill, New York

Zeithaml, V. A. (2000), Services Marketing, profitability and the economic worth of customers: What we know and what we need to learn, Journal of the Academy of Marketing Science, Vol. 28, Issue 1, pp. 67-85

Zeithaml, V.A., Bitner, M.J., Gremler, D.D. (2013), Services marketing: integrating customer focus across the firm, McGraw Hill, New York

Zimmermann, J. (1997), The Different Centres of Control, Mastering Management, Financial Times / Pitman Publishing 